International medical practices

\title{
The modernisation of general practice in the UK: 1980 to 1995 and beyond. Part II
}

\author{
Steve Iliffe
}

\section{The 1990 contract}

\begin{tabular}{|l|}
\hline Aims of 1990 contract for GPs \\
\hline - to give consumers better choice by \\
providing more information about \\
local services, increasing \\
competition between providers, and \\
making it easier to change doctors \\
- to make the terms of service more \\
specific, aiming at cloning the new \\
services already developed by better \\
practices throughout primary care \\
to make the remuneration system \\
more performance related, so that \\
GPs would have an incentive to \\
respond more to both what patients \\
want and franchisors demand \\
- to strengthen GPs' contractual \\
relationships with the newly named \\
Family Health Service Authorities \\
to ensure greater value for money in \\
the services provided through \\
general practice \\
\hline
\end{tabular}

Box 1

Keywords: general practice, healthcare management

\section{Department of Primary Health Care, University College London Medical School, Whittington Hospital (Archway Site), London N19 5NF, UK S Iliffe}

Part I of this paper was published in the April 1996 issue of the Postgrad Med F, pp 201-6.

Accepted 12 December 1995
A new contract for general practitioners (GPs), proposed by the Government in $1989^{1}$ and implemented despite intense professional opposition in 1990 , was an example of the unilateral tightening of franchisee contracts by a franchisor seeking standardisation of an increasingly diverse range of services, and with hindsight seems an almost inevitable consequence of the changes that occurred in general practice in the $1980 \mathrm{~s}$. The Government's intentions in proposing the new contract are shown in box 1 .

It met with a storm of protest from many GPs and the revised version negotiated by the General Medical Services Committee of the British Medical Association was rejected by over $70 \%$ in a national ballot.

The 1990 contract had a range of provisions. It increased the proportion of income derived from capitation fees from around $45 \%$ to $60 \%$, and reduced the size of the salary component as a proportion of total income. Other changes included a capitation supplement designed to reward doctors for practising in deprived areas or isolated communities, or for treating the very elderly. A postgraduate education allowance was introduced as an incentive to engage in continuing professional education, target payments were offered to those organising systematic approaches to preventive medicine and capitation supplements were added for undertaking child health screening. Sessional fees were paid for health promotion clinics where the content was approved by the Medical Advisor to the Family Health Service Authority (FHSA), and new fees were introduced for minor surgery and registration checks - essentially a form of case finding done at first contact with new patients. A two-tier fee structure for night visits was designed to reward those GPs who did their own night visits (or worked in a local, co-operative rota) and penalise those who used a commercial deputising service.

Preparation of an annual practice report became obligatory. Full-time GPs had to be available 26 hours a week for surgeries, home visits and clinics and they or suitably trained members of the team were expected to offer elderly patients (aged 75 and over) an annual domiciliary assessment of the individual's mental and physical condition, and social environment. Patients aged 16 to 74 years not seen and screened within a three-year period were to be invited to a dedicated screening consultation.

Aside from the unilateral imposition of this new contract, GPs expressed concern that this mixed package of incentives and obligations would impair the quality of care by speeding up the consultation process, and that the emphasis on health promotion and preventive medicine ran well ahead of the evidence. Many GPs feared that the higher proportion of income derived from capitation fees would result in larger lists and less time for individual patients. Many practices, particularly those in areas of high population mobility, felt that they could not reach the high targets for child immunisation and cervical cytology, and saw this as a perverse incentive to stop these procedures completely because they were no longer financially rewarding. It was considered possible, therefore, that the contract could widen the gap in quality of care between the best and worst practices.

The Government believed that more competition was needed within the National Health Service (NHS) and had, therefore, required practices to make more information about their services available to patients, as well as making it easier for people to change doctors. This was seen as a potentially wasteful diversion of resources and energy, since the consumerist model of healthcare still did not appear to be the most appropriate one for general practice, even allowing for the changes that had occurred in public attitudes and expectations during the 1980s. Most people still registered with their nearest doctor, knew nothing about their new practice and showed little inclination to seek information. ${ }^{3}$ Many only registered when they were ill and those in greatest need of healthcare were least likely to be able to 'shop around' for it. 
The emphasis in the new contract on preventive activities and health promotion clinics also caused concern because of its potential impact on the day-to-day care of patients. Although there is evidence that GPs can have a small but significant impact in helping patients to give up smoking ${ }^{4}$ and reduce their 0 alcohol consumption, ${ }^{5}$ some preventive activities in the contract were of 0 ? unproven value. For example, stress management clinics could be reimbursed 0 but their rationale rested on limited evidence that biofeedback and relaxation $\varrho$ might reduce blood pressure and other cardiovascular risk factors. ${ }^{6}$ The lack of scientific evidence for some activities that attracted fees led to the abandonment $\stackrel{\mathbb{Q}}{c}$ of this form of remuneration in favour of incentives to develop practice data sets $c$ of a limited range of risk factors (smoking, blood pressure, family history, diet and BMI, exercise habits and alcohol consumption) and to structure healtho promotion interventions designed to achieve the goals set in The health of the $\frac{\bar{\sigma}}{\bar{T}}$ nation $^{7}$ around these data sets. ${ }^{8}$

A meta-analysis of studies on screening of older people has suggested that this may result in an increased uptake of services and a reduction in mortality, ${ }^{9}$ but ${ }_{\mathscr{N}}$ the important components of a screening programme are still open to debate. It is still not clear which elements of the elderly assessment in the contract will yield $\stackrel{\circ}{-}$ sufficient useful information to make them worthwhile, nor whether population $\vec{\omega}$ screening is superior to opportunistic case finding. ${ }^{10}$ It is also unclear how effectively community services can respond to the increased demands that mighto be made upon them as a result of the systematic assessment of the elderly population.

\section{The internal market and general practice}

The 1990 GP contract was part of a broader reform of the NHS which includes 0 plans relevant to primary care in the White Paper Working for patients, ${ }^{11}$ ] according to which, larger general practices could apply to hold their own budgets to obtain a defined range of services to hospitals. In effect, this meant that some general practice franchisees could opt to extend their local autonomy $\frac{\mathbb{\mathbb { D }}}{3}$ even further, at the price of running greater risks, in order to catalyse the internal market in the NHS, where both hospitals and community services were being shifted from a centrally managed structure onto the franchise basis pioneered in $₫$ general practice. Family Practitioner Committees were reformed on business? lines with a clear remit and accountability and became FHSAs, and prescribing budgets were introduced into general practice to place downward pressure on expenditure on medicines.

\section{FUND HOLDING}

Whilst a few GPs embraced the concept of budget holding with enthusiasm at the $\overrightarrow{\vec{\partial}}$ outset, ${ }^{12}$ there was widespread concern about the possible adverse effects of 3 budget holding for practices and patients, including fears that equity of access to services would be undermined and that the administrative structure required would become a considerable extra burden for busy practices. ${ }^{13}$ Concern at the $\frac{\hat{O}}{3}$ threat to equity remains unabated, but the administrative overload has been circumvented by cash support for investment in management skills and 3 information technology, so that an increasing number of GPs have been drawn towards fund holding.

However, despite the expansion of fund holding to cover $40 \%$ of the population by 1995 , this innovation has become a policy problem for the NHS. First hailed as a success, ${ }^{14}$ it now seems dogged by limited advantages, high costs and unintended consequences. So far the only area where fund-holders have a demonstrable advantage over traditional franchisees is in reducing prescribing? costs. ${ }^{15,16}$ This is a government objective, but success in cost containment tells us $\tilde{o}$ nothing about either the quality of care, which may decline as medicine costs are cut, nor the long-term economic costs of short-term savings on prescribing, which may be considerable. ${ }^{17}$

The economic costs of fund holding are substantial, and include both open costs like management fees, subsidies for computerisation and administrative $\stackrel{\oplus}{+}$ costs in the practice from the billing and contract review processes, as well as $\frac{0}{0}$ hidden costs like staff time in FHSAs, Trust hospitals and the Audit $\stackrel{\circ}{\mathbb{D}}$

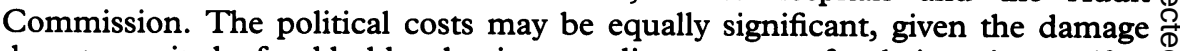
done to equity by fund holders buying speedier treatment for their patients - 'fast tracking' - and growing doubts about the fund-holding project's overall value.

Fund holding became so problematic for three reasons. Firstly, fund-holders $ᄋ$ usually cannot act as ruthless purchasers. Not only is there a contradiction between patient advocacy and resource rationing, but local providers may not $\overline{0}$ always be influenced by fund-holders' interests and choice of provider may be limited or non-existent. ${ }^{18}$ Secondly, fund-holders are as much a threat as an 
opportunity for local health policy. Fund-holders' decisions about placing resources are primarily budget-led because the pressure to avoid overspending is so great. Overspent fund-holders may simply lack the money to adhere to wider health policies. Finally, no school of general practice sees itself as simply having a gatekeeper function, but fund-holding as currently pursued stresses the role of the prudent gatekeeper. The costs of specialist care may be reduced by better chronic disease management, and through primary and secondary prevention in general practice, but the opposite may also be true. A mechanism that encourages reduced referral or prescribing on the assumption that other forms of treatment will develop to make this reduction possible is running far ahead of the evidence.

This came about because fund holding has developed as an ideological construct, not a scientific hypothesis. Fund holding is an incentive evolved from the Bosanquet and Leese micro-economic model of general practice development $^{19}$ and has been promoted by 'ignorant experts' (Alan Maynard, unpublished) but never tested in pilot studies, despite authoritative advice. ${ }^{20}$ Designed as a political solution to 'kick start' the NHS internal market, fundholding has become an end, not a means to an end. ${ }^{21}$

This promotion of an untested economic mechanism meets the needs of some GPs, since it addresses the division in British medicine between generalist and specialist ${ }^{22}$ by attempting to invert the power relationship, whilst also touching on the omniscience beneath the surface of generalism (generalists can do anything, including determine the pattern of specialist care). It also creates a managerial career option within general practice, in parallel with the vocational training structure, the medico-political career path and the hierarchy of academic practice. In a profession needing modernisation but locked within the uniformity of franchising, fund-holding may represent a new opportunity for personal development.

\section{AUDIT}

The proposals for indicative prescribing budgets are illustrative of the current preoccupation with economic efficiency. There is a danger that economic measures may take precedence over measures of quality of care in shaping the development of general practice. Working for patients ${ }^{11}$ proposed that a comprehensive programme to audit the quality of medical care should be developed. As part of this, a medical audit advisory group has been established by each FHSA. GPs' terms of service will be amended to include a requirement to participate in medical audit once satisfactory arrangements have been made locally. However, few managers and doctors agree on what audit entails, how it will work in practice, what it will cost and what its benefits will be. ${ }^{23}$ The National Audit Office found that Family Practitioner Committees had no coherent information strategy and relied for information on the quality and effectiveness of services on complaints, formal and informal contact with practitioners and comments from Community Health Councils. ${ }^{24}$

\section{The future}

The wide range of services and quality of care provided in general practice has been a source of concern to many health professionals, as well as to politicians and the public. It is unlikely that any future government will return to a situation in which general practice is not monitored and regulated by contractual mechanisms to ensure a more uniform quality of care. The logic of the franchise model appears inescapable. There is evidence, however, that the attributes considered important by patients are considerably different from those given priority by government (box 2). ${ }^{25}$ Nor are they closely related to the characteristics fostered by the 1990 contract. Amongst the criteria originated by government, only health checks for adults (which were later abandoned) and regular screening for cancer were widely considered to be important.

Discussion about quality of care tends to focus on the structure of premises Factors viewed as important by patients

- friendly and encouraging staff having personal knowledge of them

- an unhurried doctor who listens

- being seen by the same doctor on most occasions

- a nurse working on the premises

- rapid availability of appointments

- short waiting times and staffing levels or the process of care such as the recording of important data in medical records or the use of particular investigations. Only a small proportion of research in general practice is directed towards assessing the outcome of care, ${ }^{26}$ but the need to develop a comprehensive set of outcome measures has been acknowledged. ${ }^{27}$ Clearly there are considerable problems in developing such measures, particularly in primary care where many problems are self-limiting, many patients present with problems which are difficult to define, and the number of patients with any single major medical condition seen in a given year are limited. Nevertheless it should be possible as a first step to measure the process of management of some common chronic medical conditions such as hypertension, diabetes and asthma using indicators such as blood pressure, blood 
glucose and/or glycosylated haemoglobin, and peak flow rate, respectively. Comparisons within a single practice over time may be a useful indicator of the effectiveness of changes in practice organisation, and audit of this kind will probably become obligatory in general practice in the near future.

\section{GUIDELINES AND AUDIT}

Management of chronic medical problems in the community would be enhancedڤ by the use of guidelines which are acceptable to hospital doctors, GPs and, where relevant, other health professionals. ${ }^{28}$ Such guidelines should be regularly updated and modified in the light of local experience and could be incorporated $\stackrel{\complement}{\hookrightarrow}$ into local postgraduate and continuing medical education programmes and $\overrightarrow{\vec{F}}$ could also form the basis for part of the audit programme of FHSAs ando purchasing authorities. Peer review of referrals to specialists and of the management of disease may also be a catalyst for improving care. ${ }^{29}$

Services which practices are expected to provide should be properly tried and $\stackrel{\Phi}{\Phi}$ tested. The compulsory introduction of untried procedures increases workload without adequate justification and makes it more difficult to evaluate the usefulness? or otherwise of such procedures because it then becomes impossible to conduct: controlled trials. Policy decisions which affect the NHS should be implemented on $\overrightarrow{\vec{\omega}}$ an experimental basis where possible to test their effectiveness and feasibility except when the information is available from previous well-conducted studies.

Although GPs have reacted negatively to large parts of the NHS reforms, ${ }^{30} 3$ there is now broad acceptance of the role of FHSAs in monitoring workload, $N$ prescribing and referrals. Morrell has suggested ${ }^{31}$ that an audit committee of appointed by the FHSA should assess each practice on the basis of: premises, equipment, records, team work, services, teaching and research, contribution to ${ }_{G}$ the NHS. The assessment of the audit committee together with an annual reporto from each practice would form the basis of a grading from 1 to 5 on which the basic practice allowance would be calculated.

\section{MANAGEMENT OF PRIMARY CARE}

Although FHSAs have been given greater responsibility for planning primary care, they have little tradition of planning and there is a need for them to acquire individual members of staff with epidemiological and planning skills. There is a $\vec{\oplus}$ role, for instance, for doctors with a training in general practice and epidemiology. as consultants to FHSAs. This may be the resting place of the new kind of doctor: advocated by Tudor Hart, ${ }^{32}$ who will be aided by their fellow GPs' use of morbidity data bases held in their practices. Rapid developments in technologyo are occurring which are making it possible for practices to undertake a range of investigations not previously within their reach. Critical evaluation of such technology will be necessary if it is to be used appropriately. Closer co-operation $\overrightarrow{\overrightarrow{0}}$ between FHSAs and purchasing authorities, as well as local authority social 3 services departments and voluntary organisations will be necessary if comprehensive care is to be provided. ${ }^{33}$

There are a range of impediments to effective collaboration including differences in organisation and culture of the independently contracted GP. and the salaried employees of the Trusts. With the more explicit contractual 3 obligations of GPs, it should be possible to identify those areas in which individual practices agree to provide services and thus to avoid unnecessary duplication or gaps in services. In those practices which do not intend to provide 0 a paediatric surveillance service, for instance, it might be possible to 'attach' a clinical medical officer to the practice. In Newcastle upon Tyne, the Localo Medical Committee and the Community Health Services Management Team $\mathrm{N}$ have published a joint statement of intent. ${ }^{34}$ Initiatives such as this, which ? proposes co-operation on specific issues, could form a useful model planning $N$ primary care elsewhere in the country.

monitoring the state of health of the
practice population and producing an annual report comparing local with regional and national health statistics

- surveillance of local environmental hazards and infectious diseases

- planning of care, including maintaining chronic disease and disability registers

- auditing the effectiveness of preventive programmes

- evaluating the effect of medical intervention on the population perhaps through a network of research practices

\section{ACCOUNTABILITY}

It has been suggested that GP groups might eventually serve neighbourhood units of 10000 or so envisaged by the Cumberledge Report as a planning unit for $\stackrel{?}{+}$ community nursing. As this is about the size of an electoral ward the possibility $\frac{T}{0}$ exists of creating a locally elected machinery of accountability. ${ }^{32}$ This GP consortium could function as a medical officer of health for their own practice $\frac{\mathrm{Q}}{\mathbb{\mathrm { Q }}}$ population. ${ }^{35,36}$ Possible tasks for such a group are listed in box 3 .

\section{DEPRIVATION}

The targets for Health for all in Europe include a commitment to give special attention to high-risk, vulnerable and underserved individuals and groups. In the

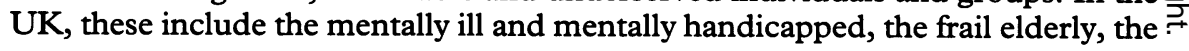


physically disabled, alcohol and drug abusers, patients with HIV and members of some ethnic minority groups. There is a need to develop explicit co-ordinated policies for these groups and description of the practice strategy for such groups should be a part of practice reports. Similarly, a more explicit commitment to reducing inequities in health will be necessary to achieve the goal of reducing, by at least $25 \%$ by the year 2000 , differences in health levels between different population groups within countries. In the UK, social class differences in ischaemic heart disease mortality are widening. ${ }^{37}$ There are wide differentials in infant mortality by social class and immunisation rates are lower amongst lower social classes. ${ }^{38}$

It has been shown that a sustained campaign by a primary healthcare team can raise the uptake of preventive care of patients in a severely deprived area to a level which in some cases exceeded that of a neighbouring community which was better endowed. Such an approach required an opportunistic strategy supplemented by a written communication on two occasions and involved health visitors in encouraging attendance. Extra clerical staff were needed to mount the programme. ${ }^{39}$ Although the deprivation allowance goes some way towards recognising the increased workload for GPs in deprived areas, a clearer commitment to reducing inequities is needed.

\section{Options for change}

There are several broad themes which are prominent in discussion of the future of primary care. One of these is the balance between competition and cooperation. Increasing competition between hospitals and between practices may reduce the potential for clinical collaboration, for instance between hospital and community services. Competition between Health Maintenance Organisations (HMOs) in the US promotes more cost effective and efficient care but in the UK the situation is very different. Healthcare expenditure is less than $40 \%$ that of the US per capita and there is state health provision for the whole population. HMOs can reduce their workload and costs by taking on a predominantly fit, relatively young population, whereas the Health for all approach emphasises the importance of catering for high risk and vulnerable groups.

A co-operative approach can most effectively identify the appropriate balance of care between hospital and community and is likely to make most efficient use of limited resources, avoiding unnecessary duplication and excessive emphasis on procedures at the expense of communication with and caring for patients. Greater emphasis could usefully be directed towards improved mechanisms for co-operation within the NHS, rather than fostering a superficial spirit of competitiveness which will favour the articulate well, rather than the vulnerable sick. Complacency in the NHS could be countered by adopting targets at practice, FHSA and purchasing authority level which provide evidence of serious intentions to improve care. ${ }^{40}$

Because fund holding is closest to the HMO model, and has become a policy problem, its future is uncertain. A moratorium on recruitment to fund holding is needed so that its cost-effectiveness can be evaluated, ${ }^{41}$ with a realistic time-scale for such evaluation, probably of about three to five years. ${ }^{42}$ Pilot projects in advanced fund holding practices will demonstrate whether purchasing all services, including social care, can make a difference to public health and the quality of specialist services. Complex questions need to be asked about outcomes for patients, rather than just about cash-flows, and fund holding needs to be measured against its alternatives to gauge its real value. ${ }^{43}$

If fund holding is not to be the answer for the development of general practice, would other types of incentives help expand the range of primary care services and improve their quality? Response to economic incentives can be very variable, which has prompted some analysts to propose that management interventions are needed to deal with family doctors who fail to respond 'rationally' to economic incentives. ${ }^{44}$ Others regard the development of teams working from purpose designed premises in $40 \%$ of practices, over one decade, as evidence of a strong response to incentives. ${ }^{45}$

The economic incentives in the 1990 contract are complex, with a mixture of positive and negative incentives in the same package. For example, targets for immunisation of children and for cervical smear testing have been achieved faster than anticipated, not only through target payments but also because practice incomes were threatened by the reduction in basic practice allowance. These complex incentives seem to be powerful, but it is unknown whether they raise the health status of the population as much as they do the income of the practice. Incentives may have the perverse effect of increasing inequalities in healthcare, either through the unequal provision of services or through their unequal uptake. 
Single-handed practices responded less than bigger practices to the health promotion clinic incentives, ${ }^{46}$ yet it is frequently the areas that these practices serve that need disease prevention most. Even if incentives can be designed which overcome this perversity, people also respond in different ways to inducements to 0 improve their health, so that inequalities in the uptake of cervical cytology tests of and other health promotion activities will persist within practice populations. ${ }^{470}$ The increased emphasis on capitation payments and incentives for health promotion activity may also be creating a bias against the ill. ${ }^{48}$

The quality of the activity stimulated by incentives may not be high. The $\stackrel{\mathbb{D}}{\varrho}$ growth of minor surgery in general practice is an example of incentives $ᄃ$ promoting quantitative rather than qualitative improvements in care. Increased $\overrightarrow{\vec{F}}$ numbers of skin lesions have been removed by GPs, some of them malignant. Incomplete excision occurs more often with those GPs who took up minor surgery after $1990,{ }^{49}$ but the proportion of skin lesions with incomplete excision $\overline{\bar{\omega}}$ is also increasing as time passes. ${ }^{50}$ When an under-skilled workforce attempts to $\stackrel{\Phi}{\varnothing}$ meet the demand, but only partially succeeds, the potential exists for an increase in workload for specialist surgical services, which have to respond to treatment $\vec{a}$

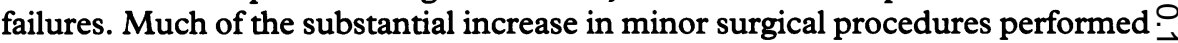
in general practice after the introduction of the new contract has occurred $\vec{\omega}$ amongst patients who would not otherwise have been referred to specialists. ${ }^{51}$

American experience of incentives for doctors suggests that they increase the $\frac{0}{7}$ intensity of medical practice, ${ }^{52}$ but in the UK context increased time given to $\frac{3}{.}$. patient contact and reduced time allocated to other work, like education and N communication, is seen as a threat to the quality of medical care. ${ }^{53}$ The of organisation of general practice, including the incentives built into it, has less $-\overrightarrow{0}$ impact on how doctors work than the characteristics of the population and the local economy. ${ }^{19,54}$ Incentives may become over-valued as an approach to 0 promoting innovation and growth at a time when adequate resources for the development of general practice are not available. Enhanced funding for primary $\bar{s}$ care may be the necessary precondition for the kinds of developments now being sought. Tighter management of general practice, with re-accreditation and short- $\frac{\mathbb{\Phi}}{3}$ term contracts might be necessary to guide rapid development of the discipline, but these would be the price that doctors would have to pay for more resources.

A recent discussion paper on the future of general practice ${ }^{55}$ attempts to $\vec{\oplus}$ outline a new way of working in primary care. It contains three basic arguments. $\%$ Firstly, GPs can only avoid the imposition of quality control by NHS managers $D$ by promoting peer-controlled re-accreditation and audit. Nevertheless increasing managerial control of general practice is here to stay. Finally, the profession should negotiate a more favourable contract that emphasises quality of care.

Acceptance of quality of care as a central concern would be the final defeat of $\stackrel{\mathbb{Q}}{\mathscr{Q}}$ the traditional defenders of general practice, coming as it does some 15 years $\overrightarrow{\overrightarrow{0}}$ after the Royal College of General Practitioners dared to speak of unacceptably 3 low standards of practice, ${ }^{56}$ and nearly a decade after the eulogies of General practice: a British success. ${ }^{57}$ However, bad practice is hard to face and it is easier to find scapegoats than accept that the variable quality of primary care derives in part from professional isolation, the rapid development of medical science itself $\frac{}{3}$. and the fatigue of being on a treadmill.

The GP-friendly contract outlined by Bogle ${ }^{55}$ emphasises the practice rather than the individual GP as the provider, seeks to make delegation of work to other professionals more secure, and dissects current workload into core general $\circ$ medical services (within normal working hours), out-of-hours services, and special services like minor surgery, dispensing and community care needs assessment. Local negotiation would deal with local variations, and practices would be given a budget for services, staff, prescribing and development. Quality $\%$ control would be established through regular practice review and professional re- $N$ accreditation.

This may work in the rural and suburban areas where general practice is already relatively well developed, but it seems less likely to work in the cities. 0 With the proposed model the best practices with the most ambitious programmes for staff growth and service development will compete with their less organised $\stackrel{\mathcal{P}}{?}$ neighbours for resources. It is difficult to see how the new proposals will eliminate variations in the quality of care; they may exacerbate them, as weak $\frac{\mathbb{D}}{\mathbb{D}}$ practices become relative losers.

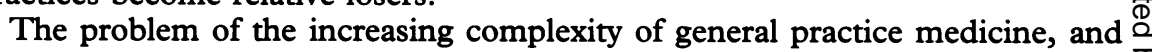
the increasing demands made upon it, will not go away. An alternative strategy? identifies GPs' autonomy as the source of unacceptable variation in standards of $\delta$ care, ${ }^{32}$ and emphasises management, planning and salaried general practice integrated into a broader primary care framework. ${ }^{58}$ This approach may be more practical than the traditional franchise structure in the cities, where complexity 
and demand may be highest and, if resourced adequately, may allow rapid improvement in service quality. This strategy may yet allow GPs to escape from the problems of an extending franchise. In a recent discussion document the General Medical Services Committee reviewed the advantages and disadvantages of a salaried service for GPs, and commented that previous arguments for and against this option often had been exaggerated. ${ }^{59}$ A subsequent ballot of GPs yielded a majority in favour of a salaried option, and more than $10 \%$ in favour of a salaried service for all. ${ }^{60}$

Until now the idea of salaried general practice has never been accepted by the majority of GPs, ${ }^{22}$ despite the fact that GPs in the armed services, working in deputising services and as trainees are salaried. ${ }^{59}$ The US experience of salaried family physicians working in HMOs suggests that there are advantages in integrating care, maintaining technical skills and knowledge and avoiding perverse incentives, ${ }^{61}$ but there are also opportunities for exploitation in profitdriven organisations. ${ }^{62}$ In Britain most pressure for a salaried service has come from doctors working in deprived areas with high workloads, facing high demand from poor facilities. ${ }^{63}$ The new contract for GPs appears to have worsened the circumstances of some doctors, especially women, and has renewed the call for a salaried option..$^{60,64,65}$

Although conceptual frameworks for evaluating the effectiveness of different ways of remunerating primary care doctors have been discussed, ${ }^{66,67}$ there is only scanty empirical evidence from trials of salary versus fee-for-service payment, ${ }^{68}$ and the results are equivocal. There is one precedent for a speedy and easy transition to salaried status, in Sweden, ${ }^{69}$ but the lack of good evidence about the efficacy of this form of remuneration necessitates careful study.

\section{Conclusion}

General practice in Britain cannot avoid further significant change, but whatever organisational changes occur in the next decade, the essential features, such as the defined list of patients, the gatekeeper role of the GP and the development of the primary care team, are unlikely to be lost. A key question, however, is whether primary care will conform to prevailing political and cultural values or, by responding in a scientific spirit to current challenges, become the foundation of a restructured NHS.

1 Health Departments of Great Britain. General Practice in the National Health Service. The 1990 Contract, 1989.

2 Pringle $M$. The quality divide in primary care. BMF 1989; 299: 470.

3 Salisbury CJ. How do people choose their doctor? $B M Y$ F 1989; 299: 608-10

4 Russell MAH, Wilson C, Baker CD. Effect of general practitioners' advice against smoking. BMF 1979; 2: 231 -5.

5 Wallace P, Cutler S, Haines AP. Randomised trial of general practitioner intervention in patients with excessive alcohol consumption. BMf 1988; 297: 663-8.

6 Patel C, Marmot MG, Terry DJ, Carruthers M, Hunt B, Patel M. Trial of relaxation in reducing coronary risk: four year follow up. $B M \mathcal{F} 1985$; 290: $1103-6$.

7 Department of Health. Health of the nation: a strategy for health in England. London: HMSO,
1992 . 1992.

8 NHS Management Executive. GP contract health promotion package: amendments to the statement of
fees and allowances. London: Department of fees and allowances. Londo

9 Stuck AE, Siu AL, Wieland GD, Adams J, Rubestein LZ. Comprehensive geriatric assessment: a meta-analysis of controlled trials. Lancet 1993; 342: $1032-6$.

10 Iliffe S. Screening the elderly: two steps forward, one step back? In: The Medical Annual 1993/4 Fry J, Bouchier-Hayes T, eds. Avon: Kingham Publications, 1993.

11 Secretaries of State for Health, Wales, Northern Ireland \& Scotland. Working for patients. LonIreland \& Scotland.
don: HMSO, 1989.

12 Houghton K. Peak practices. Health Service $f$ 1993; 103: 26-7.

13 Leese B, Smedley E. Costing GP budgets. Health Service f 1989; 96: 1310.

14 Glennerster $H$, Owens $P$, Matsaganis M. A foothold for fundholding. London: Kings Fund Institute, 1992.

15 Bradlow J, Coulter A. Effect of fundholding and indicative prescribing schemes on general practitioners' prescribing costs. BMF 1993; 307: 1186-9.
16 Maxwell M, Heaney D, Howie JGR, Noble S. General practice fundholding: observations on prescribing patterns and costs using the defined prescribing patterns and costs using the defined

17 Teeling-Smith G. The economics of prescribing and under-prescribing. In: Wells FO, ed. Medicines: responsible prescribing. Belfast: Queens University, 1992

18 Freudenstein U. Fundholding from the inside. Med World 1993; 13: 10-11.

19 Bosanquet N, Leese B. Family doctors and economic incentives. Aldershot: Dartmouth, 1989. 20 Smith R. Words from the source: an interview with Alain Enthoven. BMF 1989; 298: 1166-8.

21 Willis A. Who needs fundholding? Health Service ₹ 1992; April: 24-5.

22 Honigsbaum F. The division in British medicine. London: Kogan Page, 1979.

23 Walshe K. A clear case for audit. Health Services 7 1989; 96: $1244-5$

24 National Audit Office. The management of family practitioner committees. London: HMSO, 1988.

25 Haigh-Smith C, Armstrong D. Comparison of criteria derived by Government and patients for evaluating general practitioner services. $B M \mathcal{F}$ 1989; 299: 494-6.

26 Iliffe S, Haines AP. Development in British General Practice. Fam Med 1989; 21: 169-70, 175-76, 229-30.

27 Department of Health. Caring for people. London: HMSO, 1989.

28 Grimshaw JM, Russell IT. Effect of clinical guidelines on medical practice: a systematic guidelines on medical practice: a systematic 342: $1317-22$.

29 Haines A, Hurwitz B. Clinical guidelines; report of a local initiative RCGP Occasional paper 58, London: Royal College of General Practitioners, 1992.

30 Whitfield M, Wood N, Wright F. Responses by general practitioners in Avon to proposals for general practice in the White Paper Working for Patients. BMf 1989; 298: 1224-6.

31 Morrell D. The new general practitioner contract: is there an alternative? $B M \mathcal{F} 1989 ; 298$ : $1005-7$.
32 Hart JT. $A$ new kind of doctor. London: Merlin Press, 1988.

33 Marks L. ed. Planning primary care. King's Fund Centre, 1989.

34 Brown C, van Zwanenburg TD. Primary and community care health services in Newcastleupon-Tyne - a joint statement of intent. $\mathcal{F} R$ Coll Gen Pract 1989; 39: 164-5.

35 Mant D, Anderson P. Community general practitioner. Lancet 1985; ii: 1114-7.

36 Hart JT. Community general practitioners. $B M F$ 1984; 288: 1670 - 3 .

37 Marmot MG, McDowall ME. Mortality decline $\&$ widening social inequalities. Lancet 1986; ii: $274-6$.

38 Townsend P, Davidson N, eds. The Black report inequalities in health London: Pelican, 1988.

39 Marsh GN, Channing DM. Narrowing the health gap between a deprived and an endowed community. BMF 1988; 296: 173-6.

40 Barley S. Primary health care: the new steps. $B M F$ 1989; 298: 69-70.

41 Drummond M, Crump B, Hawkes R, Marchment $M$. General practice fundholding. $B M \mathcal{F}$ 1990; 301: 1288-9.

42 Bain J. Budget holding in Calverton: one year on. $B M F$ 1992; 304: $971-3$.

43 Eve $R$, Hodgkin $P$. In praise of non-fundholding practices. BMf 1991; 303: $167-8$.

44 Taylor D. Primary care. In: Maxwell R, ed. Reshaping the National Health Service. Oxford: Roshaping the National Health Service. Ox,

45 Bosanquet N. Health care in the 1990s: Perestroika and the NHS. In: Harrison A, Gretton J, estroika and the NHS. In: Harrison A, Gretton J,
eds. Health Care UK 1989, Oxford: Policy eds. Health Care

46 Gillam SJ. Provision of health promotion clinics in relation to population need: another example of the inverse care law? $\mathrm{Br} F \mathrm{Gen}$ Pract 1992; 42 $54-6$.

47 Waller D, Agass M, Mant D, Coulter A, Fuller $A$, Jones $L$. Health checks in general practice: another example of inverse care? $B M \mathcal{F} 1990$ 300: $115-8$. 
48 al-Bashir, Armstrong. Preferences of healthy and ill patients for style of general practitioner care: implications for workload and financial incentives under the new contract. $\mathrm{Br} \mathcal{F}$ Gen Pract $1991 ; 41: 6-8$

49 Bull AD, Silcoks PB, Start RD, Kennedy A. General practitioners, skin lesions and the new contract. F Public Health Med 1992; 14: 300-6.

50 Brown PA, Kernohan NM, Smart LM, et al. Skin lesion removal: practice by general practitioners in Grampian Region before and after tioners in Grampian Region before and a

51 Lowy A, Brazier J, Fall M, Thomas K, Jones N, Williams BT. Minor surgery by general practitioners under the 1990 contract: effects on hospital workload. $B M F$ 1993; 307: 413-7.

52 Hemenway D, Killen A, Cashman SB, Parks CL, Bicknell 'WJ. Physicians' responses to financial incentives. $N$ Engl $\mathcal{f}$ Med 1990; 322: 1059-63.

53 Calnan M, Groenewegen PP, Hutten J. Professional reimbursement and management of time in general practice. Soc Sci Med 1992; 35: $209-$
54 Kristiansen I, Mooney G. The general practitioner's use of time: is it influenced by the remuneration system? Soc Sci Med 1993; 37: 393-9.

55 Bogle I. General practice: which way forward? - a discussion document London: General Medical Services Committee, 1993.

56 Royal College of General Practitioners. Evidence to the Royal Commission on the National Health to the Royal Commission on the National Health

57 General practice: a British success. London: Gen7 General practice: a British success. London:

58 The future of primary care. London: Medical The future of primary care.
Practitioners Union, 1992 .

59 General Medical Services Committee. Your choices for the future. London: BMA, 1991.

60 Electoral Reform Ballot Services. Your choices for the future: a survey of GP opinion. London: General Medical Services Committee, 1992.

61 Relman AS. Salaried physicians and economic incentives. $N$ Engl f Med 1988; 319: 784.

62 Scovern H. Hired help; a physician's experience in a for-profit staff-model HMO. $N$ Engl $¥ \mathrm{Med}$ 1988; 319: $787-90$.
63 Robson J. Salaried service - a basis for the future? BMF 1981; 283: 1225-7.

64 Gibbons B. The case for salaried GPs. Health Service f 1991; 101: 10.

65 A salaried service - why now, and how? London: Medical Practitioners Union, 1991.

66 Pincus HA. Assessing the effects of physician $O$ payment on treatment of mental disorders in primary care. Gen Hosp Psychiatr 1990; 12: 239 .

67 Kahn HS, Orris P. The emerging role of salaried physicians: an organisational proposal. $\mathcal{f}$ Public Health Policy 1982, 3: 284-92.

68 Hickson GB, Altemeier WA, Perrin JM. Physi- $c$ cian reimbursement by salary or fee-for-service: effect on physician practice behaviour in a randomised prospective study. Paediatrics 1987; 80: $344-50$.

69 Bygren LO. Doctors on salary. Scand $\mathcal{F}$ Soc Med 1989; 17: $225-6$.

\section{Medical Anniversary \\ HANS CHRISTIAN JOACHIM GRAM, 13 SEPTEMBER 1853}

Hans Christian Joachim Gram (1853-1938) was born in Copenhagen, son of a professor of law. He qualified in medicine (1878) and joined Dr Carl Friedlander's department of pathology in Friedrichshain in Berlin (1883) where he devised his technique for distinguishing Gram-positive from Gram-negative bacteria. He returned to Copenhagen where he became, in turn, professor of pharmacology and of medicine, wrote extensively, and had a large private practice. Just before he died in November 1938, when he was 85 years, he published an article on the serum treatment of patients with type III pneumococcal pneumonia. 